\title{
Foreword to the Special Section on Rocky Plateaus
}

This Issue of the Journal of Ecological Society includes a research section with peer-reviewed research on rocky plateaus of Northern Western Ghats. The idea was conceived while discussing with various groups conducting research and conservation action in the region, with special emphasis on rocky plateaus.

Research on rocky plateaus at present spans a range of subjects from taxonomy, ecology, community use to conservation action and advocacy. However, only a small fraction of it, one related to taxonomy and ecology, finds a place in scientific journals. The readership of such journals is limited to scientists, and they are rarely accessed by citizens from other disciplines and conservation practitioners. Considering the diverse subjects being researched, any publication arising from them will be placed in separate disciplines, effectively diffusing the focus from "rocky plateaus", a sensitive, highly fragile habitat and its multiple dimensions, which should find a place in regional conservation planning.

The solution to this problem was suggested by the Editorial team for The Journal of Ecological Society. It was planned that for one issue, the research section of the journal will accept research papers and articles on the special habitat of Rocky Plateau. The papers can now be read and reflected upon collectively by the wide diversity of readers of the journal. At the same time, the research finds a perfect niche for interdisciplinary research, not offered by other journals. This has become possible only due to the far- reaching vision of Prakash Gole, founder of Ecological Society, and the team working for more than two decades to establish the journal and to create a conducive atmosphere for interdisciplinary research and action at grassroots level.

This issue includes two research papers and an article, each, in its own way, documenting the impact of human activities on the ecological processes in rocky plateau ecosystems.

Very less has been published on the hydrogeology of springs arising from Western Ghats hill tops. It is one of the most critical issues for human well-being in the region, and has been severely neglected by water managers of the region. The paper on the spring sheds in the Mahabaleshwar-Panchgani region documents effect of human activities on springs, and ecological processes that lead to flowing of springs. It identifies critical issues in spring research and conservation which should form part of water conservation and management initiatives in future.

A review of bauxite mining on rocky plateaus and restoration efforts identifies challenges for technical restoration of the rocky plateau's complex ecosystem. This review will certainly prove useful for area managers involved in regulating mining activities in and near Western Ghats, which is a biodiversity hotspot.

Wind farm development has been one of the major activities on rocky plateaus in the last decade. Although identified as renewable and clean energy, the allied infrastructure development has high landscape level impacts on biodiversity and ecology. Study on a high density wind farm in Satara identifies landscape level changes and their impact on microhabitats and associated biodiversity on the plateaus. It makes innovative use of landscape imaging tools, and creates a set of methods for analysing landscapes level changes. I hope that in coming years, these tools and methods will contribute significantly to the landscape research in Western Ghats.

Each of these papers will be read and appreciated for their unique findings, but we hope the readers will also see the linkages amongst them as they all address the issue of human activities and their impact on a sensitive ecosystem.

I cannot thank enough the entire editorial team of The Journal of Ecological Society. It has been a great learning process for me to discuss and analyse research, together with a team of highly experienced editors, a truly multidisciplinary team. Interactions with them brought out several key points in each contribution, making them stronger and more focused. The research on rocky outcrops is yet in its exploratory phase. It has great potential for future studies, which need to be taken up by keen researchers with an open mindset necessary for interdisciplinary science. I am sure these contributions will set the trend for future research.

Dr. Aparna Watve aparnawatve1@gmail.com 